\title{
De-gender them! Gendered vs cooperative division of housework - cross-cultural comparison of Polish and Norwegian students
}

\author{
Natasza Kosakowska-Berezecka ${ }^{1}$ (1) $\cdot$ Paweł Jurek ${ }^{1} \cdot$ Tomasz Besta $^{1} \cdot$ Lubomiła Korzeniewska $^{1} \cdot$ Beate Seibt $^{2}$ \\ Published online: 12 July 2018 \\ (C) The Author(s) 2018
}

\begin{abstract}
Domestic work has gendered meaning and content of both masculinity and femininity is strongly embedded in the cultural context. In our article, across three studies we analyse the perception of household duties and their division between partners in two countries differing with regard to gender equality levels: Norway and Poland. In our Study 1, Polish $(N=64,40$ women, $\left.M_{\text {age }}=19.97\right)$ and Norwegian $\left(N=45,27\right.$ women, $\left.M_{\text {age }}=24.46\right)$ students rated the typicality of domestic duties for women and men in Poland and in Norway. Our results show that feminine-typed or masculine-typed household duties are perceived as less gendered in Norway than in Poland. In the second Study, using a sample consisting of students and internet users from Poland $\left(N=207,92\right.$ women, $\left.M_{\text {age }}=27.15\right)$ and Norway $\left(N=126,85\right.$ women, $M_{\text {age }}=26.84(S D=10.87)$, we investigated whether there are Polish-Norwegian differences with regard to willingness to be more involved in household obligations. Overall, Norwegian men and women were more willing to perform household tasks. This result also found confirmation in results obtained with larger representative samples in Study 3. Using European Social Survey records of 889 Poles (429 women, $M_{\text {age }}=47.02$ ) and 990 Norwegians (452 women, $M_{\text {age }}=49.38$ ) we compared data concerning men's and women's perception of their and their partners' contribution to housework. Our results show that cultural context can relate to the perception of household duties that are perceived more gender-neutral in Norway than in Poland.
\end{abstract}

Keywords Gender stereotypes · Cross-cultural comparisons · Gender equality within housework · Gendered domestic duties

\section{Introduction}

Men across cultures are under pressure to conform to norms such as agency, dominance, pursuit of high social status, and above all avoidance of femininity (Berent et al. 2015; Mahalik et al. 2003). Hence being involved with domestic work is not considered to be a man's job but a woman's job, which men should not engage in (Poortman and Van der Lippe 2009; Bosson and Vandello 2013). The extent to which housework is equally divided between women and men depends on the level of gender equality in a given country. In countries with higher levels of gender equality, men and women perform more similar roles in the society and it is more common for men to be occupied with domestic work than in countries with

Natasza Kosakowska-Berezecka

natasza.kosakowska@ug.edu.pl; http://www.ug.edu.pl/en/

1 Institute of Psychology, University of Gdańsk, Bażyńskiego 4, 80-952 Gdańsk, Poland

2 Department of Psychology, University of Oslo, Oslo, Norway lower gender equality (Glick \& Fiske, 2001; Wood and Eagly 2012). As posited by the biosocial construction model, cultural beliefs about gender roles correspond with people's observations of the activities of women and men in their society, thus if people observe women caring for children and doing house chores then they feel that women are more suited to performing domestic work than men (Eagly and Steffen 1984; Wood and Eagly 2012). These gender role inferences, in turn, promote sex-differentiated behavior that is also manifested in women's and men's readiness and obligation to be involved in domestic work - scientific findings invariably reveal that regardless of gender equality levels of the country, most household bargaining ends up with women being more responsible for housework (Coltrane 2000; Ehrenberg et al. 2001; Fuwa 2004).

Discrepancy between men's and women's share in household chores comprises a visible gender gap in the family. This gap is specifically noticeable when tasks are grouped in masculine-typed and feminine-typed housework (Schneider 2012). According to Tai and Treas (2013), there is almost universal division of chores into masculine-typed (yard work, minor repairs) and feminine-typed work (e.g. laundry, cleaning, 
sick care) based on data from 32 countries. The latter group of duties consists of chores, which are strongly avoided by men (Treas and Tai 2010), as they may be seen as time-consuming and monotonous, contrary to masculine-typed tasks such as home maintenance, car repair, yard work that are considered more recreational and episodic (Bianchi et al. 2006). Apart from the biosocial construction model (Wood and Eagly 2012), another potential explanation for why men tend to refrain from performing feminine-typed activities is the fear of not being perceived as manly enough. Manhood is built along the lines of agency and an anti-femininity mandate which discourages men to be involved in activities which are feminine and communal such as childcare and domestic work (Bosson and Vandello 2013; Caswell et al. 2014; KosakowskaBerezecka et al. 2016b; Schneider 2012). Avoiding housework can be thus one of the ways in which men compensate for threats to their masculinity and avoid negative appraisal from other society members who expect men to be manly and refrain from feminine tasks (Caswell et al. 2014; KosakowskaBerezecka et al. 2016b). As a result, masculine partners do not take up enough share of gendered household obligations, which would allow women to be more visible in the labour market (Kosakowska-Berezecka et al. 2016b).

\section{Culture and Gender Roles}

Cross-cultural studies have shown an almost universal pattern for women to be thought of as communal and for men - agentic (Guimond et al. 2006; Williams and Best 1990). Williams and Best (1990) in their cross-cultural study focused on typicality of certain traits for women and men in society, however no study up to date investigated cross-cultural perceptions of domestic duties and willingness of women and men to perform feminineand masculine-typed household activities. In our studies, we concentrated on the domain of household activities and we measured the extent to which they are considered to be typically feminine or masculine in two countries: Poland and Norway. These countries differ with regard to gender equality levels, with Norway considered to be the model gender egalitarian country (Global Gender Gap Report, 2014). We assume that domestic duties are perceived as less gendered in countries with higher gender equality levels as men in these countries are more often seen performing them than in countries with lower gender equality levels.

Norway often serves as a good example of a country where both social policies (such as father quota, Brandth and Kvande 2015) and cultural values promoting gender equality (Holter 2014) encourage couples to implement egalitarian practices regarding division of domestic and parental work. Among many indicators of gender equality levels, especially one indicator recently has gained importance as detector of gender equality in a country - namely the amount of time a man spends on household duties and childcare (Holter 2014). Norwegian men contribute the most to housework and related chores according to the report by Organisation for Economic Cooperation and Development (OECD) (Better Life Index, 2014). They spend $180 \mathrm{~min}$ a day doing housework (although their feminine partners nevertheless spend more time, with 210 min declared on average) and thus have one of the highest scores concerning time spent on housework among other 34 OECD countries analyzed in the report. Norway is also ranked 2 nd in the world with a score of .85 on the Global Gender Gap Report (World Economic Forum, Global Gender Gap Index (GGGI) 2015). On the other hand, Polish women spend on average 296 min daily on housework and care for family members, whereas men spend on average $157 \mathrm{~min}$ daily (OECD 2014) and Poland scores in Global Gender Gap Report visibly lower: 51 st in the world and scored .71 on the GGGI (2015). Thus, we might assume that gender relations are less egalitarian in Poland than in Norway. However, these results do not show which household duties are divided in which way between partners.

\section{Current Study}

In our article, we present results of three studies, which contribute to research on the gendered approach to household labour by looking at women's and men's perceptions rather than general abstract gender ideologies, as they can be biased by the desire to give socially desired opinions. To our knowledge, no other study has tested this line of research among Polish and Norwegian samples, which differ significantly with regard to gender equality levels.

In Study 1, we analyse the extent to which feminine- and masculine-typed household duties are perceived as gendered by Polish and Norwegian students. Since the level at which a given activity is perceived as gendered might relate to actual willingness to perform it, in Study 2 we wanted to verify whether there are Polish-Norwegian actual differences with regard to women's and men's willingness to be more involved in fulfilment of feminine-typed and masculine-typed household obligations. In Study 3, we analysed how partners in Poland and Norway perceive their contribution and their partner's contribution to housework to see if the cooperative model of gender equality will be more visible in Norway than in Poland.

Analysing division of household duties between partners in a cross-cultural perspective allows us verify whether women and men are more cooperative and egalitarian with regard to housework division in more gender egalitarian Norway than in Poland. We assume that as Norwegian men contribute the most to housework (OECD, Better Life Index, 2014), it might be perceived in a less gendered way, namely housework activities will be seen as less feminine in Norway than in Poland. 


\section{Study 1}

In Study 1, we investigated Polish and Norwegian perceptions of typicality of domestic duties for women and men. Results of several reports and studies on division of household labour indicate that Norwegian men are more involved in household and parental duties than Polish men (OECD 2014). Based on this, also following the biosocial construction model (Wood and Eagly 2012) we hypothesized (hypothesis 1, H1) that in Norway domestic activities will be less gendered - femininetyped activities will be perceived as less feminine and masculine-typed activities will be perceived as more feminine than in Poland.

\section{Method}

Participants Undergraduate students of University of Gdansk, Poland ( $N=64,40$ women, $M_{\text {age }}=19.97(S D=1.50)$ and students of University of Stavanger, Norway $(N=45,27$ women, $M_{\mathrm{age}}=24.46(S D=2.89)$ voluntarily participated in this study. The data collection took place during students' regular classes and in both countries our participants were students of social sciences.

Materials and Procedure On the basis of reports analysing distribution of household duties between women and men prepared by Public Opinion Research Center (cf. Hipsz 2013; Szczepańska 2006) and a literature review (cf. Schneider 2012), we selected 25 household activities. Our participants were asked to rate (using 7-point Likert-type scales) to what extent the given activity is typical for women in their society (Norwegian and Polish respectively). The questionnaire was in Polish (in Poland) and in English (in Norway, as English is a language of instruction in many courses at the university).

\section{Results and Discussion}

We used $t$-tests for independent samples to analyze differences in perception of feminine typicality for all domestic duties in Poland and Norway. Our analysis confirmed our hypotheses: feminine-typed activities (doing laundry, changing the bedding, daily shopping, sweeping the floor, removing dust, vacuuming, washing dishes, cleaning the floor) were all seen as less feminine activities in Norway than in Poland. Conversely, masculine-typed activities (small household repairs and car cleaning) were seen as more feminine in Norway than in Poland (see Table 1).

Overall, 16 household activities from the list of 25 activities were rated as visibly feminine (mean score above 5 in 7-point Likert-type scale) in Poland and only 9 in Norway, which falls in line with the biosocial construction model. Thus, household activities in Norway are perceived as less gendered than in Poland (Wood and Eagly 2012). Comparing the overall femininity score of household activities from the list (excluding the activities which were perceived as low in femininity in both countries with the mean score below 4) we can see that in Norway these activities are seen as less feminine than in Poland $(M=4.95(.70)$ vs $M=5.6(1.01), t(106)=3.662, p<.001)$, whereas the masculinetyped activities which were considered to be low in femininity are actually perceived as more feminine in Norway than in Poland $(M=3.27$ (.96) vs $M=2.68(1.24), t(106)=3.662, p$ $<.01)$. There are also activities such as taking care of sick children at home, buying clothes for children, watering the flowers, helping children with their homework, cleaning the bathroom, window cleaning, feeding pets, pet wash, weeding the garden, trimming bushes, mowing the grass, cleaning the garage for which we did not find significant differences between countries. Surprisingly, taking out the trash is an exception in the list as it belongs to activities performed daily and is considered similarly low in femininity in both countries - probably this might be universally masculine household activity (Hipsz 2013).

Based on the results from Study 1 we can conclude that domestic duties in Norway are seen as less gendered than in Poland and confirm hypothesis 1. In Study 2, we wanted to see whether Norwegian men and women are more willing to undertake gender-incongruent tasks when living with a partner, as it is more common for men and women to be seen doing gender-incongruent tasks. Following the biosocial construction model (Wood and Eagly 2012), we also wanted to test whether seeing a man or a woman performing gender atypical tasks would lead our study participants, both in Poland and in Norway to be more willing to undertake such tasks.

\section{Study 2}

In Study 2, we wanted to verify whether there are PolishNorwegian differences with regard to women's and men's willingness to be more involved in feminine-typed and masculinetyped household obligations. Based on the results of Study 1, we put forward a hypothesis that Norwegian men will be more willing than Polish men to engage in gender incongruent duties - namely in feminine-typed household duties (hypothesis 1, $\mathrm{H1}$ ), as they are seen as less feminine-specific as shown in Study 1. Likewise, we expected Norwegian women to be more willing to engage in gender incongruent duties, namely masculine-typed household duties (hypothesis, H2) as they are seen as less masculine specific as also shown in Study 1. We also wanted to verify whether Polish men would be more willing than Norwegian men to engage in gender congruent activities such as masculine-typed household activities (hypothesis 3, H3) and whether Polish women would be more willing than Norwegian women to perform gender congruent duties, namely feminine-typed household duties (hypothesis 4, H4). 
Table 1 Perception of feminine typicality of activities - Poland and Norway $-\mathrm{t}$-test independent samples

\begin{tabular}{|c|c|c|c|c|c|c|}
\hline \multirow[b]{3}{*}{ Activities } & \multicolumn{6}{|c|}{ Perception of feminine typicality } \\
\hline & \multicolumn{2}{|c|}{ Poland $(N=63)$} & \multicolumn{2}{|c|}{ Norway $(N=45)$} & \multirow[b]{2}{*}{$t$} & \multirow[b]{2}{*}{ Cohen's d } \\
\hline & $M$ & $S D$ & $M$ & $S D$ & & \\
\hline Taking care of sick children at home & 6.19 & 1.35 & 5.73 & 1.28 & 1.78 & .35 \\
\hline Doing laundry & 6.16 & 1.22 & 5.62 & 1.07 & $2.37 *$ & .47 \\
\hline Buying clothes for children & 6.08 & 1.45 & 5.84 & 1.14 & .91 & .18 \\
\hline Changing the bedding & 6.08 & 1.36 & 5.42 & 1.22 & $2.59 * *$ & .51 \\
\hline Daily shopping & 6.06 & 1.20 & 4.91 & 1.18 & $4.94 * *$ & .97 \\
\hline Sweeping the floor & 6.02 & 1.36 & 4.47 & 1.36 & $5.83 * *$ & 1.14 \\
\hline Removing dust & 6.00 & 1.38 & 4.73 & 1.32 & $4.79 * *$ & .94 \\
\hline Preparing meals & 5.94 & 1.33 & 5.38 & .96 & $2.40 *$ & .48 \\
\hline Vacuuming & 5.87 & 1.31 & 5.04 & 1.00 & $3.56^{* *}$ & .71 \\
\hline Watering the flowers & 5.78 & 1.72 & 5.20 & 1.47 & 1.80 & .36 \\
\hline Washing dishes & 5.73 & 1.33 & 4.64 & 1.21 & $4.33 * *$ & .86 \\
\hline Helping children with their homework & 5.56 & 1.41 & 5.13 & 1.34 & 1.56 & .31 \\
\hline Mopping the floor & 5.48 & 1.64 & 4.91 & 1.18 & $1.97 *$ & .40 \\
\hline Cleaning the bathroom & 5.44 & 1.69 & 5.18 & .98 & .95 & .19 \\
\hline Cleaning the fridge & 5.43 & 1.76 & 4.53 & 1.73 & $2.63 * *$ & .52 \\
\hline Window cleaning & 5.22 & 1.74 & 4.70 & 1.27 & 1.69 & .34 \\
\hline Feeding pets & 4.63 & 1.69 & 4.58 & 1.10 & .18 & .04 \\
\hline Washing pets & 4.40 & 1.54 & 4.22 & 1.52 & .58 & .18 \\
\hline Weeding the garden & 4.35 & 1.76 & 4.02 & 1.53 & 1.00 & .20 \\
\hline Taking out the trash & 3.43 & 1.73 & 3.82 & 1.35 & -1.27 & .25 \\
\hline Small household repairs & 3.24 & 1.71 & 4.38 & 1.43 & $-3.65 * *$ & .72 \\
\hline Trimming bushes & 2.70 & 1.63 & 3.07 & 1.50 & -1.19 & .24 \\
\hline Mowing the grass & 2.49 & 1.63 & 2.93 & 1.52 & -1.40 & .28 \\
\hline Cleaning the car & 2.29 & 1.38 & 2.93 & 1.54 & $-2.28 *$ & .44 \\
\hline Cleaning the garage & 1.95 & 1.38 & 2.47 & 1.41 & -1.89 & .37 \\
\hline
\end{tabular}

Note. $* p<.05, * * p<.01$
Additionally, we assumed that if our participants saw a picture where the household duty was performed by the opposite gender than assumed by gender stereotypes (gender incongruent behaviour such as e.g. removing the dust by men), this might help in de-gendering the activity by indicating that men and women can do similar tasks. Thus, we also tested whether manipulating the sex of the person depicted as performing a given activity (enhancing sex-typing of a given activity vs reducing sex-typing of a given activity) might lead to increase in men's or women's willingness to perform it regardless of the participant's country. Specifically, we predict that reducing sex-typing of a masculine activity should make women more willing to perform it, and reducing sex-typing of a feminine activity should make men more willing to perform it (hypothesis 5, H5).

\section{Method}

Participants Poles $\left(N=207,92\right.$ women, $M_{\text {age }}=27.15$ $(S D=11.13)$ and Norwegians $\left(N=126,85\right.$ women, $M_{\text {age }}=$
$26.84(S D=10.87)$ voluntarily participated in this experiment. The sample included a mix of undergraduate students, postgraduate students of University of Gdansk, Poland and University of Oslo, Norway and Internet users.

Materials and Procedure To measure participants' willingness to perform various household duties, we used pictorial presentations of activities. We additionally manipulated the sex of the target person presented in the picture. Each participant was randomly assigned to one of two experimental conditions: gender-congruent activities (enhancing sex-typing) versus gender-incongruent activities (reducing sex-typing). Participants were asked whether they were willing to perform a given household activity shown in the picture when living with a partner, indicating either YES or NO. Eight household activities were shown to them, based on the result from Study 1. Five of these were stereotypically feminine tasks: vacuuming, doing laundry, removing dust, preparing the meals and ironing (added to the list) and 3 were stereotypically masculine tasks: cleaning the car, replacing a light bulb and 
drilling a hole in the wall (the last two given as examples of household repairs). There were two experimental conditions: gender-congruent activities (where women presented in the pictures engaged in feminine-typed activities, and men engaged in masculine-typed activities) and gender incongruent activities (when men presented in the picture engaged in feminine-typed activities, and women engaged in masculinetyped activities) (see examples in Fig. 1).

In order to calculate the individuals' score for "willingness to perform a feminine-typed activity" we counted the average proportion of "yes" answers for the five feminine-typed activities ( $\alpha=.76$, "preparing meals" was excluded due to low reliability); to calculate the variable "willingness to perform a masculinetyped activity "we counted the average proportion of "yes" answers for the three masculine-typed activities, $(\alpha=.65)$.

\section{Results and Discussion}

In order to verify hypothesis $\mathrm{H} 2-\mathrm{H} 6$ about the differences in willingness to do feminine- and masculine-typed household activities between Polish and Norwegian students we conducted two ANOVAs with 2 (condition: gender-congruent activities versus gender-incongruent activities) by 2 (nationality) by 2 (gender) design, separately for the willingness to perform feminine- and masculine-typed activities as dependent variables.

Our analysis showed a main effect of nationality for feminine-typed household activities $F(1,333)=44.12, p$
$<.01, \eta^{2}=.12$, with Norwegian participants more often than Polish participants indicating to be willing to perform them. We also noted a main effect of gender for feminine-typed household duties $F(1,333)=13.46 p<.01, \eta^{2}=.04-$ men were overall less often willing to perform feminine-typed household activities. There were no main effects of condition nor any interaction effects for feminine-typed household duties. In case of masculine-typed household activities, our analysis showed a main effect of nationality, $F(1,333)=$ $5.35, p<.05, \eta^{2}=.02$, with Norwegian participants more often than Polish participants indicating to be willing to perform them. In addition, we found a gender main effect, $F(1,333)=$ $59.41, p<.01, \eta^{2}=.16$, with men more often than women indicating to be willing to perform them. Finally, we obtained a main effect of experimental conditions (gender-congruent activities versus gender-incongruent activities), $F(1,333)=$ $5.22, p<.05, \eta^{2}=.02$, with participants more often indicating to be willing to perform masculine-typed household activities when they were demonstrated by men. These main effects were qualified by the interaction effect between gender and nationality, $F(1,333)=7.51, p<.05, \eta^{2}=.02$. Polish men declared to be more willing to perform masculine-typed tasks than women, while the difference between Norwegian men and women was not statistically significant. The interaction Condition $\mathrm{x}$ Nationality $\mathrm{x}$ Gender was not significant, $F(1,333)=2.91, p=.09, \eta^{2}=.01$.

Thus, we confirmed that Norwegian men would be more willing than Polish men to engage in feminine-
Fig. 1 In the upper-left corner: the example of a picture of a woman performing femininetyped activity; in the lower left corner; the example of a picture of a man performing masculinetyped activity (gender-congruent activity condition). On the right side: examples of opposite situations (gender-incongruent activity condition)
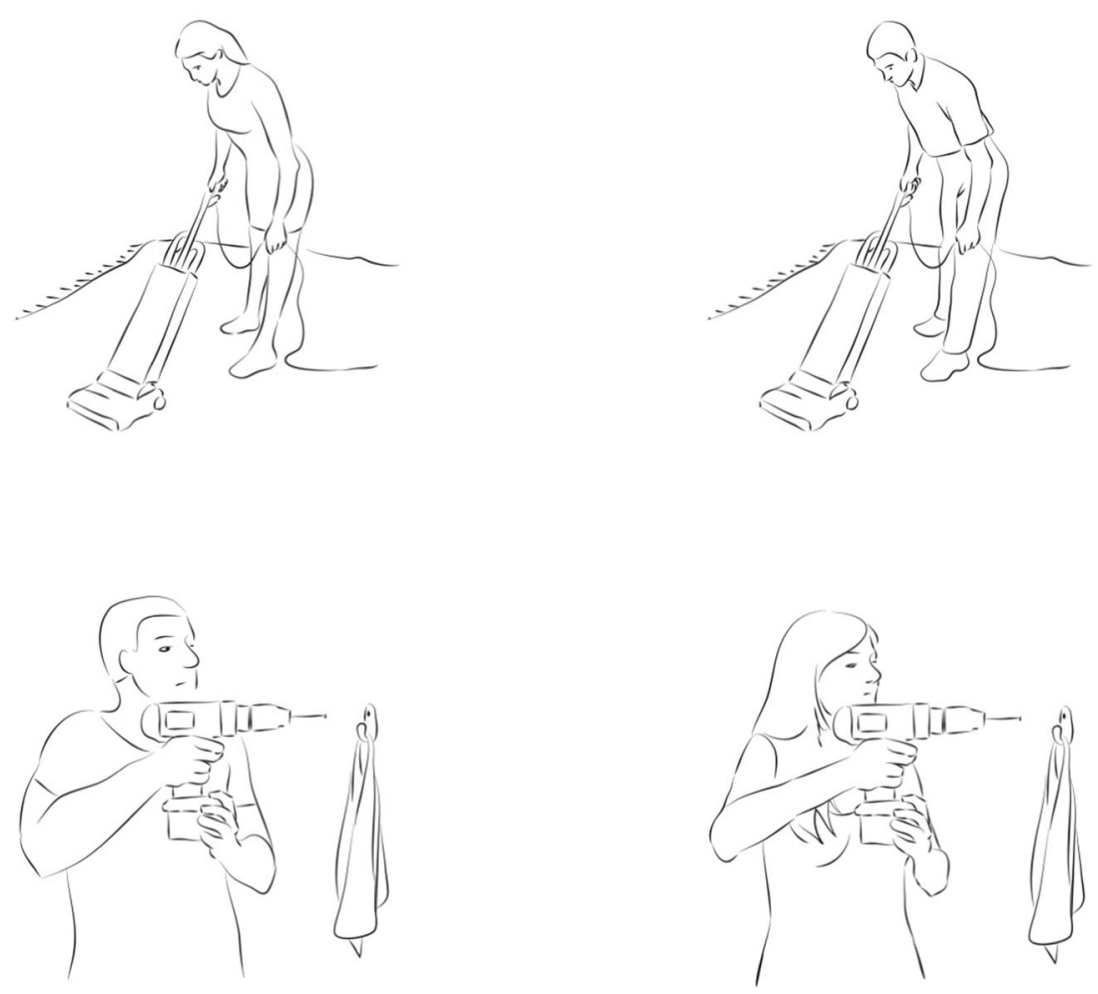
typed household duties (H1) and that Norwegian women would be more willing than Polish women to engage in masculine-typed household duties (H2). However, the more general pattern we obtained was that Norwegian men and women were more willing to engage in all household duties. Accordingly, $\mathrm{H} 3$ and $\mathrm{H} 4$ that Polish men and women would be more willing than Norwegian men and women to engage in gender-congruent duties were disconfirmed. Our hypothesis 5 regarding the gender-incongruent depiction of household chores was also disconfirmed.

Table 2 presents the results of the analysis along with the summary of simple effects ( $t$ test for independent samples).

Overall, our results showed that Norwegian women and men were more willing to perform both femininetyped household duties and masculine-typed household duties in comparison to Polish women and men. Furthermore, in line with other studies (Coltrane 2000; Ehrenberg et al. 2001; Fuwa 2004), men regardless of their nationality were less willing than women to perform feminine-typed household duties and more willing than women to perform masculine-typed household activities.

Nevertheless, both Norwegian women and men overall declared greater willingness to perform feminine-typed and masculine-typed household duties than Polish women and men. This might indicate that Norwegians realize a more cooperative model of household duties division - both women and men declared they were willing to perform household duties more so than Polish women and men. As our participants in Studies 1 and 2 were not representative of the population, in Study 3 we wanted to analyse how a representative sample of Poles and Norwegians perceive their contribution and their partner's contribution to housework to examine whether Norwegians distribute household chores more cooperatively than Poles.

\section{Study 3}

\section{Method}

Participants and Procedure In order to analyse women's and men's perception of mutual contribution within housework in the two countries we analysed the data drawn from the fifth wave of the European Social Survey (2010, ESS hereafter). We focused on the Polish and Norwegian samples, which were representative for the population to analyse women's and men's answers to the following questions: Total hours a week you personally spend on housework and Total hours a week your partner spends on housework. We assumed that in Norway, being a more gender egalitarian country the difference between total hours a week a woman and her partner spend will be smaller than in Poland, thus showing that they cooperate more within housework.

In a first step, we removed from the database European Social Survey records containing no answer and the answers "not applicable" and "do not know". Our analysis is based on 889 Poles (including 429 women, $M_{\mathrm{age}}=47.02, S D=14.88$ ) and 990 Norwegians (including 452 women, $M_{\text {age }}=49.38, S D=15.20$ ).

\section{Results and Discussion}

Using the answers to the two questions, we conducted two ANOVAs with a 2 (nationality) by 2 (gender) design on each of the two questions separately as dependent variables.

Our analysis showed a main effect of nationality for both questions: total hours a week spent on housework $\left(F(1,1879)=300.64, p<.01, \eta^{2}=.14\right)$ and total hours a week respondent's partner spends on housework (respondent's opinion), $\left.F(1,1879)=255.97, p<.01, \eta^{2}=.12\right)$. In both

Table 2 Differences between Polish and Norwegian women and men in willingness to perform masculine-typed and feminine-typed activities observing a woman/man performing gender-congruent and gender-incongruent activities

Gender-congruent activities

\begin{tabular}{|c|c|c|c|c|c|c|c|c|c|c|}
\hline \multirow[b]{3}{*}{ Dependent variable } & \multicolumn{5}{|c|}{ Women } & \multicolumn{5}{|l|}{ Men } \\
\hline & \multicolumn{2}{|c|}{ Polish $(N=43)$} & \multicolumn{3}{|c|}{ Norwegian $(N=42)$} & \multicolumn{2}{|c|}{ Polish $(N=63)$} & \multicolumn{3}{|c|}{ Norwegian $(N=20)$} \\
\hline & $M$ & $S D$ & $M$ & $S D$ & $t$ & $M$ & $S D$ & $M$ & $S D$ & $t$ \\
\hline Willing to do feminine-typed activities & $60 \%$ & $29 \%$ & $93 \%$ & $13 \%$ & $-6.70 * *$ & $54 \%$ & $37 \%$ & $71 \%$ & $31 \%$ & -1.89 \\
\hline Willing to do masculine-typed activities & $53 \%$ & $34 \%$ & $69 \%$ & $31 \%$ & $-2.20^{*}$ & $88 \%$ & $23 \%$ & $97 \%$ & $10 \%$ & $-2.28 *$ \\
\hline \multicolumn{11}{|l|}{ Gender-incongruent activities } \\
\hline & \multicolumn{5}{|c|}{ Women } & \multicolumn{5}{|l|}{ Men } \\
\hline & \multicolumn{2}{|c|}{ Polish $(N=49)$} & \multicolumn{3}{|c|}{ Norwegian $(N=43)$} & \multicolumn{2}{|c|}{ Polish $(N=52)$} & \multicolumn{3}{|c|}{ Norwegian $(N=21)$} \\
\hline Dependent variable & $M$ & $S D$ & $M$ & $S D$ & $t$ & $M$ & $S D$ & $M$ & $S D$ & $t$ \\
\hline Willing to do feminine-typed activities & $64 \%$ & $30 \%$ & $87 \%$ & $23 \%$ & $-4.03 * *$ & $51 \%$ & $35 \%$ & $75 \%$ & $40 \%$ & $-2.56^{* *}$ \\
\hline Willing to do masculine-typed activities & $48 \%$ & $33 \%$ & $67 \%$ & $34 \%$ & $-2.83 * *$ & $86 \%$ & $25 \%$ & $75 \%$ & $39 \%$ & 1.22 \\
\hline
\end{tabular}

$* p<.05, * * p<.01$ 
questions Poles declared more hours (respectively $M=19.48$, $S D=16.15$ and $M=20.52, S D=19.23$ ) compared to Norwegian (respectively $M=10.39, S D=8.06$ and $M=$ $10.75, S D=8.23$ ). Moreover, the results showed a main effect of gender for both questions: total hours a week spent on housework, $F(1,1879)=394.00, p<.01, \eta^{2}=.17$, and total hours a week respondent's partner spends on housework (respondent's opinion), $F(1,1879)=346.44, p<.01, \eta^{2}=.16$. Women declared more hours $(M=20.22, S D=14.90)$ compared to men $(M=9.84, S D=9.43)$. Men confirmed their partner's greater engagement in household chores $(M=20.49$, $S D=17.35)$ and women their partner's lesser engagement $(M=9.57, S D=9.78)$. These main effects were qualified by the interaction effect between gender and nationality for both questions: total hours a week spend on housework, $F(1,1879)=63.72, p<.01, \eta^{2}=.03$ and total hours a week respondent's partner spends on housework, $F(1,1879)=$ 49.32, $p<.01, \eta^{2}=.03$. Polish women declared significantly more time spent on household chores than Polish men, and they significantly rated their partner's involvement in these area as lower than Polish men. For Norwegians, these differences were considerably smaller (see Fig. 2 and Fig. 3).

Our results overall indicate that Norwegian men and women spent less hours than Polish men and women on housework and they share it more evenly, as seen in a smaller difference between women's and men's contributions in Norway than in Poland. Hence it seems that both women and men in Norway manifest a more cooperative approach with regard to housework division and are thus are less eager to share them along the gendered lines.

\section{General Discussion}

In line with the biosocial construction model, we showed in Study 1 that feminine-typed activities are seen as less feminine in Norway than in Poland and that masculine-typed activities are seen as less masculine in Norway. This shows that housework is perceived in a more gender-neutral way in Norway. The results of Study 1 suggest that gendered perception of

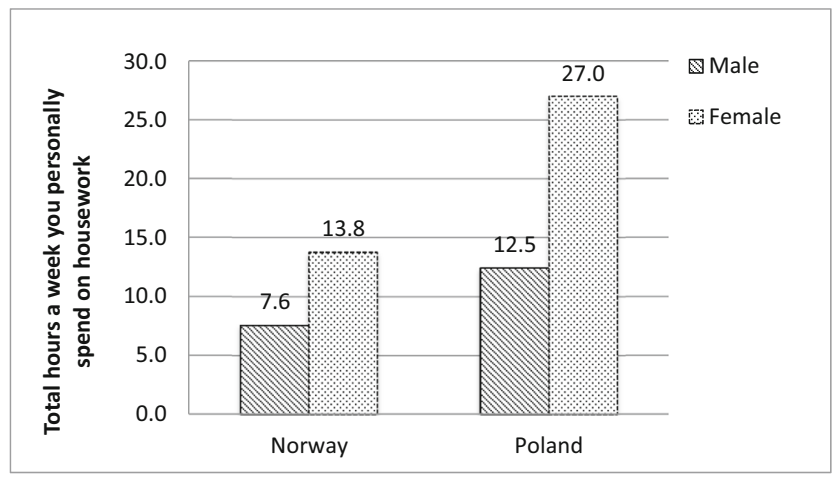

Fig. 2 The interaction effect between gender and nationality for total hours a week you spend on housework

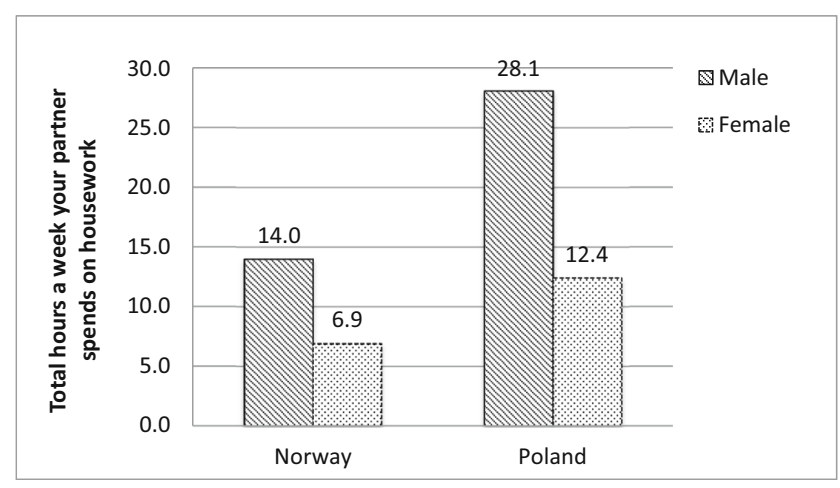

Fig. 3 The interaction effect between gender and nationality for total hours a week respondent's partner spends on housework

domestic duties contributes to our understanding of persistent gender inequalities in the division of household labour. According to our theoretical framework, the cultural context regarding gender equality more generally regulates the perception of domestic work, which in turn is seen as more or less gendered, as shown by the results of Study 1 (see also: Kosakowska-Berezecka and Karasiewicz 2014; Oyserman 2011). In Study 2, we showed that both Norwegian men and women are more willing to engage in household duties, regardless of the type of activity (feminine or masculine-typed activity) - hence their division of housework is more cooperative and egalitarian than among women and men in Poland. This result was also confirmed in Study 3 with larger samples representative of both countries, confirming that Norwegian women and men share housework more evenly than women and men in Poland. Hence, it seems that Norwegians manifest a more cooperative approach with regard to housework division and share it less along the gendered lines.

The cooperative approach to division of domestic work by Norwegians manifests itself with greater willingness to do housework and more readiness to cooperate while dividing housework with the partner in a more egalitarian way. Given that fairness and equality are important values in close relationships, contributing to relationship satisfaction and commitment (Thibaut and Kelley 1959; Walster et al. 1978), it seems likely that more willingness by men to engage in housework makes women more cooperative as well, as seen in Study 2. Hence, our results show initial evidence that de-gendering of household activities along with a more cooperative approach can lead to equalizing women's and men's contribution to domestic work, liberating women from having to carry the main burden of the housework. This in turn opens up opportunities for women to pursue their career or enjoy more leisure time. It may also increase relationship satisfaction by increasing fairness and equality, a hypothesis that awaits further investigation.

The activities encompassed by gender roles are not fixed, but are rather shaped according to a given cultural context, as posited by the biosocial construction model (Wood and Eagly 2012). Our results did not show any effect of observing 
gender-incongruent or gender congruent behaviour, thus our manipulation was not successful - no matter who performed the activity overall Norwegian men and women were more willing to perform it while living with the partner than Polish participants. Nevertheless, all participants were more willing to perform masculine-typed household activities when they were performed by men. This may be related to these activities being considered more recreational and episodic (Bianchi et al. 2006) and more associated with high-status (Rudman et al., 2012). It could also be that the more familiar depiction led to more fluent processing of the pictures, thus increasing positive affect and willingness (Reber et al. 1998).

\section{Limitations of the Studies}

Our first two studies were conducted among college students who rarely fully experience the challenges of reconciling work and family life and division of household duties and our Norwegian samples of men were relatively small. This constitutes an important limitation within our findings, partially overcome in Study 3 where we analyzed data obtained from representative samples of women and men from ESS 2010. Moreover, Study 2 was a correlational one, and we could not thus infer about causality of relation between domestic duties being less gendered in Norway than in Poland and willingness of Norwegian men and women to undertake genderincongruent housework duties.

Furthermore, it is possible that our gender-incongruent depictions of household chores in Study 2 were simply not very salient, thus many participants may not have noticed or processed the incongruency sufficiently. Future studies on the effects of gender-incongruent depictions of activities should employ more salient manipulations (e.g. using more interactive materials like scripts from couples, diaries or movies).

Our results indicate that Norwegian men and women are more cooperative with regard to housework division: they are more willing to do domestic activities and are thus less eager to share them along the gendered lines. This might be connected with the fact that Norwegian women and men overall spend less time on housework. One reason for this difference could be the use of external paid help in doing housework by Norwegians, which is rare for Poles. 7\% of Norwegian adults hire someone for house-keeping duties (SSB, 2009), whereas in Poland registered home-helpers constitute less than 7 per mille of society (Pawłowska-Salińska 2012). The difference in total housework hours may also be due to Norwegians using more time-saving technologies like dish-washers, dryers and cleaning robots and buying more ready-made food. Hence, we might speculate that it is easier to share duties if there are less of them.

Overall, couples who have a more egalitarian approach towards life and division of duties will in fact distribute them more equally (Baxter et al. 2008). In-depth interviews conducted among Polish and Norwegian couples show that Norwegian couples perceive household division as a team project requiring team efforts. They actually negotiate the who, how and when of housework instead of following automatic gendered division of household duties, a behaviour which is not observed among Polish couples (Kosakowska-Berezecka et al. 2016b; Żadkowska et al. 2018).

The readiness of men and women to organize their households in a more egalitarian way varies from country to country (House et al. 2004). Cross-cultural studies indicate that there is a stable and well-defined division between a female-domestic and a male-professional world (Williams and Best 1990). This also regulates the perception of social roles and related tasks our results show that in more gender egalitarian countries household activities are less gendered than in less gender egalitarian countries.

To sum up, understanding how perceptions of activities along gender-stereotype lines influences willingness to engage in them sheds light on the distribution of housework within families. Gendered perception of domestic duties contributes to our understanding of persistent gender inequalities in the division of household labour. Looking at men, whose manhood is often built on the notion of avoidance of feminity (Bosson and Vandello 2013; Caswell et al. 2014; KosakowskaBerezecka et al. 2016a; Schneider 2012), perceiving housework as more gender neutral may help them see it as less of a threat to their masculinity. In turn, they can take on a more equal share in household obligations, making both genders more cooperative rather than antagonistic, as was the case for our Norwegian participants. If there is no a-priori distribution of household labour determined by gender, then the distribution can be bargained between the two partners, which is likely to bring more egalitarian and less gendered results. Since men's contribution to gender equality can be measured by the amount of time they spend on housework, this constitutes an important detector of gender equality of a given country (Holter 2014).

Funding The research leading to these results has received funding from the Polish-Norwegian Research Programme operated by the National Centre for Research and Development under the Norwegian Financial Mechanism 2009-2014 in the frame of Project Contract No Pol-Nor/202343/62/2013.

\section{Compliance with Ethical Standards}

Conflict of Interest The authors declare that they have no conflict of interest.

Ethical Approval All procedures performed in studies involving human participants were in accordance with the ethical standards of the institutional and/or national research committee and with the 1964 Helsinki declaration and its later amendments or comparable ethical standards.

Informed Consent Informed consent was obtained from all individual participants included in the study. 
Animal Studies This article does not contain any studies with animals performed by any of the authors.

Open Access This article is distributed under the terms of the Creative Commons Attribution 4.0 International License (http:// creativecommons.org/licenses/by/4.0/), which permits unrestricted use, distribution, and reproduction in any medium, provided you give appropriate credit to the original author(s) and the source, provide a link to the Creative Commons license, and indicate if changes were made.

\section{References}

Baxter, J., Hewitt, B., \& Haynes, M. (2008). Life course transitions and housework: Marriage, parenthood, and time on housework. Journal of Marriage and the Family, 70(2), 259-272.

Berent, J., Falomir-Pichastor, J. M., \& Chipeaux, M. (2015). Masculinity and sexual prejudice: A matter of heterosexual men's need to dissociate from women and gay men. In K. Faniko, F. Lorenzi-Cioldi, O. Sarrasin, \& E. Mayor (Eds.), Gender and social hierarchies: Perspectives from Social psychology. London: Routledge.

Bianchi, S. M., Robinson, J. P., \& Milkie, M. (2006). Changing rhythms of American family life. New York: Russell Sage Foundation.

Bosson, J. K., \& Vandello, J. A. (2013). Manhood, womanhood, and the importance of context: A reply to commentaries. Psychology of Men \& Masculinity, 14(2), 125-128.

Brandth, B. \& Kvande, E. (2015) 'Norway country note', in: P. Moss (ed.) International Review of Leave Policies and Research 2014. Available at http://www.leavenetwork.org/lp and $\mathrm{r}$ reports/

Caswell, T. A., Bosson, J. K., Vandello, J. A., \& Sellers, J. G. (2014). Testosterone and men's stress responses to gender threats. Psychology of Men \& Masculinity, 15(1), 4-11.

Coltrane, S. (2000). Research on household labor: Modeling and measuring the social embeddedness of routine family work. Journal of Marriage and the Family, 62, 1208-1233.

Eagly, A. H., \& Steffen, V. J. (1984). Gender stereotypes stem from the distribution of women and men into social roles. Journal of Personality and Social Psychology, 46, 735-754. https://doi.org/ 10.1037/0022-3514.46.4.735.

Ehrenberg, M. F., Gearing-Small, M., Hunter, M. A., \& Small, B. J. (2001). Childcare task division and shared parenting attitudes in dual-earner families with young children. Family Relations, 50, 143-154.

European Social Survey. (2010). Round 5 data (Data file edition 2.0). Bergen, Norway: Norwegian Social Science Data Services (Data archive and distributor of ESS data).

Fuwa, M. (2004). Macro-level gender inequality and the division of household labor in 22 countries. American Sociological Review, 69, 751-767.

Glick, P., \& Fiske, S. T. (2001). An ambivalent alliance. Hostile and benevolent sexism as complementary justifications for gender inequality. Am Psychol, 56(2), 109-118.

Guimond, S., Chatard, A., Martinot, D., Crisp, R. J., \& Redersdorff, S. (2006). Social comparison, self-stereotyping, and gender differences in selfconstruals. Journal of Personality and Social Psychology, 90, 221-242.

Hipsz, N. (2013). O roli kobiet w rodzinie. (Eng. On the role of women in the family. Public Opinion Research Center. retrieved $20^{\text {th }}$ July. 2014. from: http://www.cbos.pl/SPISKOM.POL/2013/K 030_13.PDF.

Holter, Ø. G. (2014). What's in it for men?: Old question, new data. Men and Masculinities, 17, 515-548. https://doi.org/10.1177/10971 84X14558237.

House, R., Hanges, P., Javidan, M., Dorfman, P. \& Gupta, V. (2004). Culture, leadership, and organizations. Thousand Oaks: Sage Publications.

Kosakowska-Berezecka, N., \& Karasiewicz, K. (2014). Jestem unikalny, więc cenię Twojąunikalność? Wpływ aktywizacji tożsamości osobistej i społecznej na postrzeganie innych - porównanie międzykulturowe Polska-indie [I am unique therefore I appreciate your uniqueness? Effects of personal and social identity priming on judgments of others: A cross-cultural comparison of Poland and India]. Psychologia Spoleczna, $9 / 1(28)$, 54-67.

Kosakowska-Berezecka, N., Besta, T., Adamska, K., Jaśkiewicz, M., Jurek, P., \& Vandello, J. A. (2016). If my masculinity is threatened I won't support gender equality? The role of agentic selfstereotyping in restoration of manhood and perception of gender relations. Psychology of Men \& Masculinity. Advance online publication. https://doi.org/10.1037/men0000016.

Kosakowska-Berezecka, N., Żadkowska, M., Gajewska, M., Wroczyńska, A., Znaniecka, M. (2016). Navigator for couples. Manual for Couples. University of Gdansk Publishing.

Mahalik, J. R., Locke, B., Ludlow, L., Diemer, M., Scott, R. P. J., Gottfried, M., \& Freitas, G. (2003). Development of the conformity to masculine norms inventory. Psychology of Men \& Masculinity, 4, 3-25. https://doi.org/10.1037/1524-9220.4.1.3.

OECD (2014). Better Life Index. OECD Publishing. Retrieved from: http://www.oecdbetterlifeindex.org/countries/canada/.

Oyserman, D. (2011). Culture as situated cognition: Cultural mindsets, cultural fluency, and meaning making. European Review of Social Psychology, 22, 164-214. https://doi.org/10.1080/10463283.2011.627187.

Pawłowska-Salińska, K. (2012). Najbardziej niewidzialny zawód w Polsce: gosposia, czylipomoc domowa [The least visible profession in Poland: housekeeper - househelp]. Retrived from: http:// wyborcza.pl/1,76842,11520362,Najbardziej_niewidzialny_zawod_ w_Polsce_gosposia_html\#ixzz4CuSLfAjn.

Poortman, A. R., \& Van der Lippe, T. (2009). Attitudes toward housework and child care and the gendered division of labor. Journal of Marriage and Family, 71, 526-541.

Reber, R., Winkielman, P. \& Schwarz, N. (1998). Effects of perceptual fluency on affective judgments. Psychological Science, 9, 45-48.

Rudman, L. A., Moss-Racusin, C. A., Phelan, J. E., \& Nauts, S. (2012). Status incongruity and backlash effects: Defending the gender hierarchy motivates prejudice against female leaders. Journal of Experimental Social Psychology, 48(1), 165-179. https://doi.org/ 10.1016/j.jesp.2011.10.008.

Schneider, D. (2012). Gender deviance and household work: The role of occupation. American Journal of Sociology, 117(4), 1029-1072.

Szczepańska, J. (2006). Men and women and share of household duties. Public Opinion Research Center. retrieved $20^{\text {th }}$ July. 2014. from: http://www.cbos.pl/SPISKOM.POL/2006/K 184_06.PDF.

Tai, T., \& Treas, J. (2013). Housework task hierarchies in 32 countries. European Sociological Review, 29(4), 780-791.

Thibaut, J. W., \& Kelley, H. H. (1959). The social psychology of groups. New York: Wiley. https://doi.org/10.2307/2092954.

Treas, J., Tai, T. (2010). Real Men Don't Do Laundry? Avoidance of Feminine-Typed Household Tasks in 34 Countries. Paper presented at the annual meeting of the American Sociological Association Annual Meeting, Hilton Atlanta and Atlanta Marriott Marquis, Atlanta, GA.

Walster, E., Walster, G. W., \& Berscheid, E. (1978). Equity: Theory and research. Boston: Allyn \& Bacon.

Williams, J. E., \& Best, D. L. (1990). Measuring sex stereotypes: A multination study. Thousand Oaks: Sage Publications.

Wood, W., \& Eagly, A. H. (2012). Biosocial construction of sex differences and similarities in behavior. In J. M. Olson \& M. P. Zanna (Eds.), Advances in experimental social psychology (Vol. 46, pp. 55-123). London: Elsevier.

World Economic Forum (2015). The Global Gender Gap Report. Retrieved April $7^{\text {th }} 2016$ from http://reports.weforum.org/globalgender-gap-report-2015/rankings/

Żadkowska, M., Kosakowska-Berezecka, N., Ryndyk O. (2018). Two worlds of fatherhood - comparing the use of parental leave among Polish fathers in Poland and in Norway. In: K. Slany, E. Guriye, P. Pustułka, M. Ślusarczyk. Migration - Ethnicity - Nation: Studies in Culture, Society and Politics. Peter Lang International Publishing House. 